\title{
Multivalued almost contractions in metric space endowed with a graph
}

\author{
ISHAK ALTUN and ÖZLEM ACAR
}

\section{ABSTRACT.}

The main goal of this paper is to introduce a multivalued almost contraction on a metric space with a graph. In terms of this new contraction, we establish some fixed point results on graph.

\section{REFERENCES}

[1] Acar, Ö. and Altun, I., Multivalued F-contractive mappings with a graph and some fixed point results, Submitted

[2] Agarwal, R. P., O'Regan, D. and Sahu, D. R., Fixed Point Theory for Lipschitzian-type Mappings with Applications, Springer, New York, 2009

[3] Beg, I. and Butt, A. R., Fixed point of set-valued graph contractive mappings, J. Inequal. Appl., 2013 (2013), 252, 7 pp.

[4] Berinde, V., Approximating fixed points of weak $\varphi$-contractions using the picard iteration, Fixed Point Theory, (2003), 131-147

[5] Berinde, V., On the approximation of fixed points of weak contractive mappings, Carpathian J. Math., 19 (2003), No. 1, 7-22

[6] Berinde, V., Approximating fixed points of weak contractions using the Picard iteration, Nonlinear Anal. Forum, 9 (2004), No. 1, 43-53

[7] Berinde, V., Iterative Approximation of Fixed Points, Springer-Verlag, Berlin Heidelberg, 2007

[8] Berinde, V. and Berinde, M., On a general class of multi-valued weakly Picard mappings, J. Math. Anal. Appl., 326 (2007), $772-782$

[9] Berinde, V. and Păcurar, M., The role of the Pompeiu-Hausdorff metric in fixed point theory, Creat. Math. Inform., 22 (2013), No. 2, 35-42

[10] Chifu, C., Petruşel, G. and Bota, M-F., Fixed points and strict fixed points for multivalued contractions of Reich type on metric spaces endowed with a graph, Fixed Point Theory Appl., 2013:203, 12 pp.

[11] Dinevari, T. and Frigon, M., Fixed point results for multivalued contractions on a metric space with a graph, J. Math. Anal. Appl., 405 (2013), No. 2, 507-517

[12] Johnsonbaugh, R., Discrete mathematics, Prentice-Hall, Inc., New Jersey, 1997

[13] Nadler, S. B., Multi-valued contraction mappings, Pacific J. Math., 30 (1969), 475-488

[14] Sultana, A. and Vetrivel, V., Fixed points of Mizoguchi-Takahashi contraction on a metric space with a graph and applications, J. Math. Anal. Appl., 417 (2014), No. 1, 336-344

Department of MATHEMatics

KIRIKKALE UNIVERSITY

FACULTY OF SCIENCE AND ARTS

71450 YAHSIHAN, KIRIKKALE, TURKEY

E-mail address: ishakaltun@yahoo.com

DEPARTMENT OF MATHEMATics

KIRIKKALE UNIVERSITY,

FACULTY OF SCIENCE AND ARTS,

71450 YAHSIHAN, KIRIKKALE, TURKEY

E-mail address: acarozlemeymail.com 